Kris Mattila, Michigan Technological University 


\section{Teaching Construction Terminology: An Interactive Approach}

In many courses the terminology must be introduced and explained before moving on to other topics. How to approach this varies by the instructor, the course, the text being used and the difficulty of the terminology. It is important to not only understand the meaning of a term but how it relates to other terms that are being discussed. The technique presented in this paper uses a modified version of a method that assists people to remember names: name association. In that method the person employing it uses some characteristic or distinctive feature of the individual to assist them in remembering the name. In the technique presented in this paper, used to remember construction terminology, it can be the individual who defines that term, the definition that was presented by the individual or the relationship to other terms that assists in remembering the definition of the term and its relationship to other terms. Examples from two different classes, an introductory construction course and an estimating course are provided. Results of using this technique are compared to a traditional lecture method using the same terms. . 